\title{
IDENTIFICAÇÃO DE COMPOSTOS AROMÁTICOS PRESENTES NO ALCATRÃO DE HULHA PROVENIENTE DA GASEIFICAÇÃO DO CARVÃO MINERAL DE CANDIOTA-RS
}

\author{
F. D. SÁ ${ }^{1}$, I. R. NUNES ${ }^{1}$, R. NASCIMENTO ${ }^{1}$, R. B. RIBEIRO ${ }^{1}$, P. B. RIBEIRO, F. P. \\ GUTERRES $^{1}$ e A. C. MUNIZ ${ }^{1}$ \\ ${ }^{1}$ Universidade Federal do Pampa, Grupo de Pesquisa em Energia e Carboquímica \\ E-mail para contato: fe.dias.sa@ gmail.com
}

\begin{abstract}
RESUMO - Na busca de novas alternativas para utilização do carvão mineral, de forma mais limpa, a gaseificação se mostra com grande potencial para seu uso. $\mathrm{O}$ principal produto é o syngas, porém, há também a formação do coproduto, denominado de alcatrão de hulha, contendo Hidrocarbonetos Aromáticos Policíclicos (HAPs). O filtrado do alcatrão produzido na planta piloto de gaseificação em leito fluidizado borbulhante, da Universidade Federal do Pampa, apresentou prioritariamente água, tolueno, fenol e antraceno. A gaseificação foi conduzida a $780{ }^{\circ} \mathrm{C}$ durante duas horas, e o alcatrão foi resfriado e coletado através de uma série de dois condensadores e uma centrífuga. Em seguida foi filtrado e analisado por cromatografia gasosa (CG-FID). Os compostos identificados constituem matéria prima base da indústria química.
\end{abstract}

\section{INTRODUÇÃO}

O carvão mineral consiste em um combustível fóssil, sólido e negro composto pela deposição de matéria orgânica no decorrer de milhares de anos (Aneel, 2010). Sendo uma das matérias-primas mais abundantes na região sul do Brasil, o carvão mineral é atualmente utilizado com combustível no processo de combustão direta para a produção de energia elétrica. É composto em sua maior parte por cinzas (53\% b.s.), com teor de umidade de $15 \%$. Essas características fazem com que a eficiência do processo de combustão seja comprometida. Nesse sentido, uma potencial opção para a utilização dessa matéria-prima é a gaseificação.

O processo de gaseificação é dividido em quatro etapas físico-químicas, distribuídas em: secagem $\left(\mathrm{T}<150{ }^{\circ} \mathrm{C}\right)$, pirólise ou desvolatilização $\left(150{ }^{\circ} \mathrm{C} \leq \mathrm{T} \leq 700{ }^{\circ} \mathrm{C}\right)$, combustão $\left(700{ }^{\circ} \mathrm{C} \leq \mathrm{T} \leq 1500^{\circ} \mathrm{C}\right)$ e a gaseificação $\left(750^{\circ} \mathrm{C} \leq \mathrm{T} \leq 1100^{\circ} \mathrm{C}\right)$. Essas etapas se tornam alto suficientes energeticamente, devido as reações que ocorrem, e tem como produto principal, o syngas (Sá, et al. 2016). Esse processo pode ser feito em diversos tipos de gaseificadores, no entanto, devido a característica do carvão nacional os gaseificadores de leito fluidizado borbulhante e circulante são os mais indicados para o processo. 
Na produção do syngas, a obtenção de coprodutos torna-se inevitável, sendo eles o alcatrão e as cinzas. O alcatrão formado é um líquido, geralmente, viscoso de cor variando do castanho ao preto, podendo apresentar odor amoniacal derivado das bases piridínicas presentes em sua composição. O alcatrão destilado a temperaturas elevadas é mais rico em hidrocarbonetos aromáticos do que parafínicos (Shreve e Brink 1980, apud Ribeiro 2016). Na prática, obtém-se os destilados crus e outros produtos são derivados a partir deles. A porcentagem de rendimentos, como mostrado na Figura 1, é representada pela área dos retângulos, e são valores médios baseados no alcatrão original. Os rendimentos variam com condições diferentes e carvões diferentes dependentes da avaliação mineral de onde o carvão é originário, bem como do processo de formação do alcatrão. Como se segue, benzeno bruto e tolueno representam uma fração de óleos leves, já o fenol representa um percentual dos óleos médios e o antraceno compõe parte do óleo de antraceno, sendo esses os principais compostos encontrados na fração do alcatrão de hulha analisado nesse trabalho.

Figura 1 - Composição do alcatrão de carvão formado.

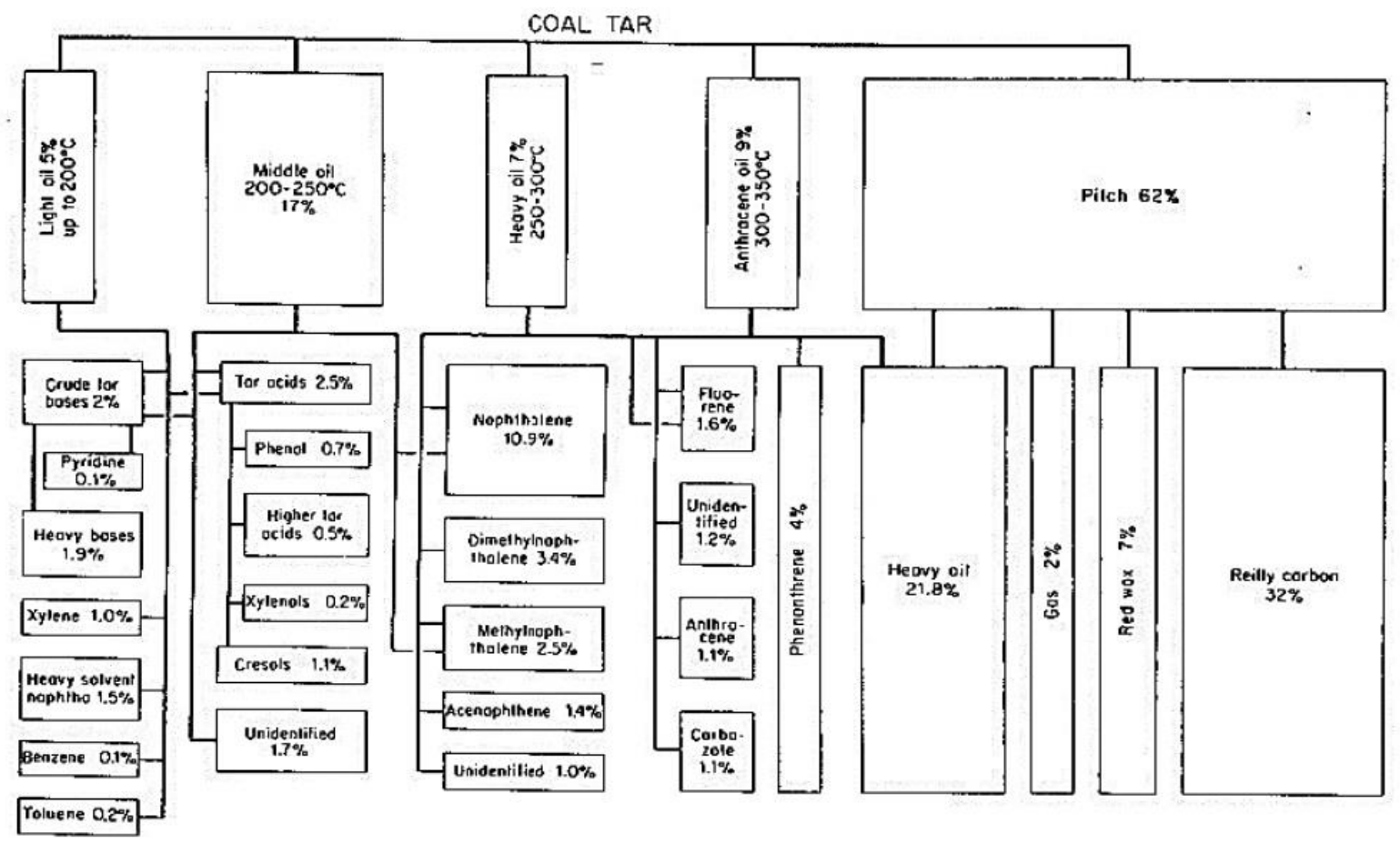

Fonte: SHREVE e BRIK, 1980.

Os Hidrocarbonetos Policíclicos Aromáticos (HAPs) são os hidrocarbonetos de maior importância ambiental devido ao seu comportamento mutagênico e carcinogênico e devem ser encontrados na fração mais densa do alcatrão, chamada de piche. São definidos como compostos orgânicos, semivoláteis, contendo dois ou mais anéis aromáticos condensados, formados por átomos de carbono e hidrogênio (Gonçalves, 2007; Lopes, 2014).

Esse trabalho teve por objetivo identificar os compostos aromáticos presentes no alcatrão de hulha originário da gaseificação do carvão mineral da jazida de Candiota-RS, através de técnica de cromatografia. 


\section{METODOLOGIA}

\subsection{Gaseificação}

O processo de gaseificação inicia-se adicionando-se seis litros de areia de quartzo 40/50 e dois litros de carvão em reator fechado. Um silo de alimentação é carregado com carvão com o diâmetro de Sauter de aproximadamente $0,42 \mathrm{~mm}$. O ventilador "plenum" é ligado em $11 \mathrm{Nm}^{3} / \mathrm{h}$, para iniciar o processo de fluidização e ligada a resistência para que o carvão atinja a temperatura de ignição, em aproximadamente $350{ }^{\circ} \mathrm{C}$. A partir do ponto de ignição, o sistema de alimentação é ligado, sendo composto por parafuso transportador e válvula rotativa seguida de nova rosca sem fim com frequência constante. O parafuso transportador do silo é ajustado para $10 \mathrm{~Hz}$. A reação ocorre até atingir o estado estacionário. O sistema possui um sistema de separação de sólidos composto por um ciclone, válvula rotativa e tambor de coleta de cinzas leves e uma série de dois condensadores e uma centrífuga para garantir a separação de líquidos (alcatrão de hulha). A Figura 2, apresenta a planta de gaseificação do Laboratório de Energia e Carboquímica da Universidade Federal do Pampa.

Figura 2 -Gaseificador de leito fluidizado do LEC.

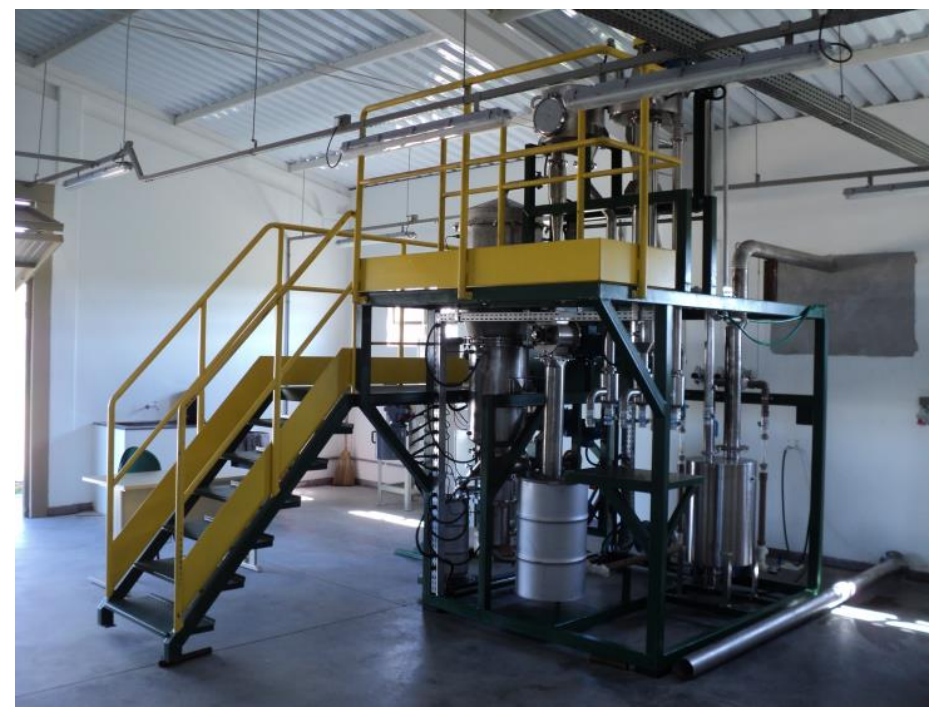

\subsection{Cromatografia}

A análise química de composição do alcatrão foi realizada em cromatógrafo gasoso da marca Shimadzu modelo GC-2014 ATF/SPL. Os parâmetros para as condições de análise utilizados foram: temperatura do forno de $45^{\circ} \mathrm{C}$, com tempo de equilíbrio de 4 minutos e uma taxa de aquecimento de $4{ }^{\circ} \mathrm{C} / \mathrm{min}$ até $280{ }^{\circ} \mathrm{C}$ ficando em equilibro por 5 minutos. A coluna utilizada foi uma Rtx-5, possuindo diâmetro interno de $0,25 \mathrm{~mm}$ e comprimento de 15 m. O gás $\mathrm{N}_{2}$ foi usado como gás de arraste na vazão de $19 \mathrm{~mL} / \mathrm{min}$. O detector usado foi um detector de ionização por chama (FID). A Figura 3, demonstra o equipamento usado. 
Figura 3 - Cromatógrafo gasoso Shimadzu utilizado na análise química.

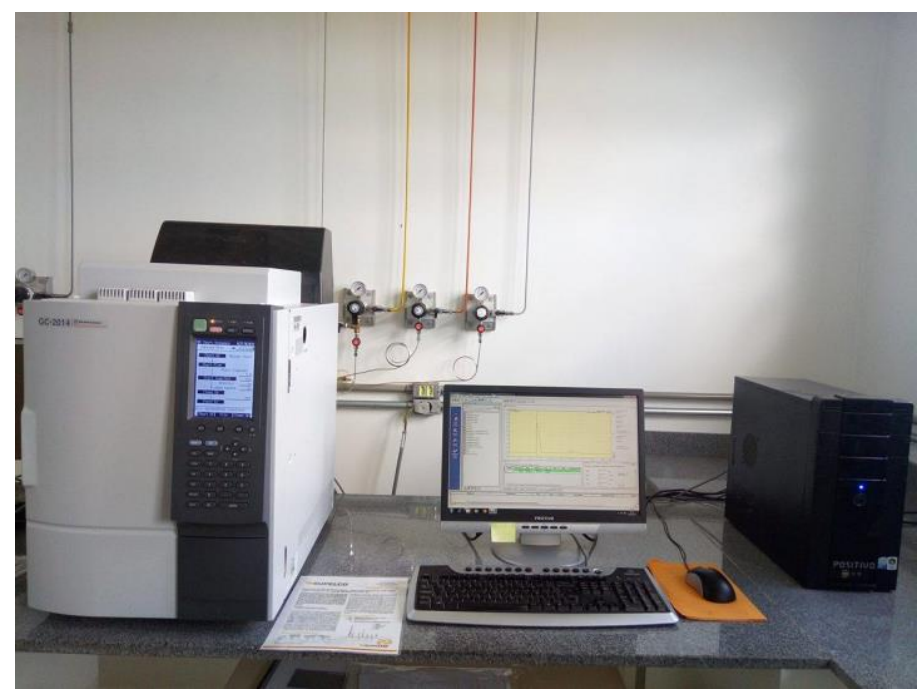

\section{RESUTADOS E DISCUSSÕES}

Para análise cromatográfica, primeiramente, fez-se a filtração do alcatrão, em papel de filtro micropore, e armazenamento do filtrado em congelador a $-10^{\circ} \mathrm{C}$. A Figura 4 , apresenta cromatograma obtido para o filtrado, em gaseificação realizada na temperatura de $780{ }^{\circ} \mathrm{C}$.

Figura 4 - Cromatograma representativo da análise realizada - (1) água, (2) tolueno, (3) fenol e (4) antraceno.

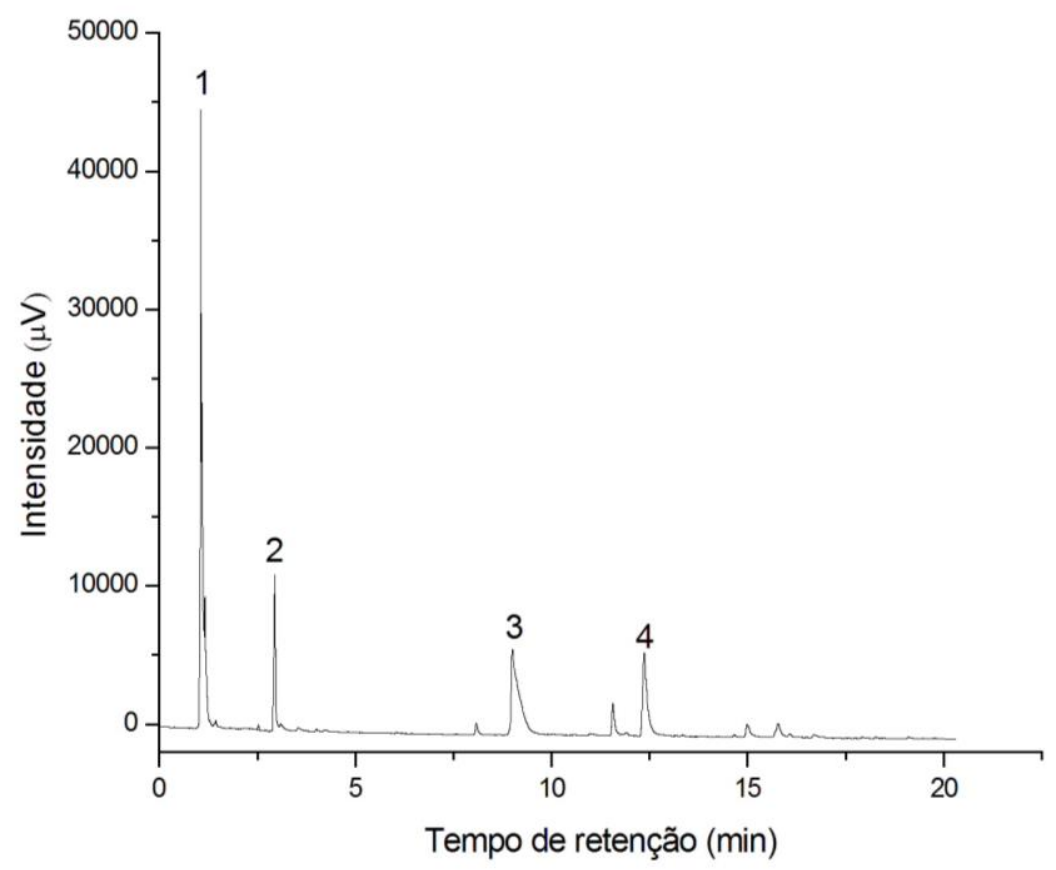


Os resultados mostrados na Figura 4, mostram maior presença de fenol no filtrado do alcatrão de hulha, concordando com o descrito por Pan et al. (2012). Segundo os autores, as alíquotas contendo tolueno, fenol e antraceno foram produzidas entre 160 e $240{ }^{\circ} \mathrm{C}$, e não continham destilados pesados. Caramão e Do Nascimento Filho (2004), realizaram uma análise quantitativa de compostos fenólicos, presentes no alcatrão de uma fábrica de cerâmica brasileira, através de cromatografia gasosa acoplada com espectrometria de massa (GC-MS), identificaram cerca de 25 fenóis nas amostras e concluíram que o alcatrão de carvão possui grandes quantidades de compostos aromáticos leves de interesse industrial. A gaseificação do carvão mineral da jazida de Candiota, contém a fração mais simples do fenol em sua composição.

Para trabalhos futuros sugere-se a realização da extração de HPAs do coque presente no alcatrão de hulha e a identificação dos compostos presentes. Também, propõe-se analisar o efeito da temperatura sobre a composição do alcatrão de hulha.

\section{CONCLUSÃO}

A partir da análise realizada observou-se que o processo de gaseificação, comparado à combustão, é uma alternativa de mitigação de impactos ambientais com grande potencial de emprego na região de Candiota/RS. Ademais, o coproduto líquido obtido da filtração do alcatrão de hulha, mostrou que o mesmo possui potencial de uso como matéria-prima para o desenvolvimento de outros produtos, pois é constituído por compostos básicos para a indústria química. Este trabalho possibilitou o conhecimento à cerca das características de parte do alcatrão de hulha, assim como perspectiva de aplicação deste coproduto, podendo ser amplamente utilizado para aplicação industrial na obtenção de explosivos, desinfetantes, cosméticos, resinas e polímeros, além de outros.

\section{REFERÊNCIAS}

ANEEL. Agência Nacional de Energia Elétrica do Brasil. Parte III - Fontes Não Renováveis: Carvão mineral. 2010

CARAMÃO, E. B.; DO NASCIMENTO FILHO, I. Quantitative analysis of phenol and alkylphenols in Brazilian coal tar. Quimica Nova, v. 27, n. 2, p. 193-195, 2004.

GONÇALVES, C. K. Pirólise e combustão de resíduos plásticos. 74 p. São Paulo: Universidade de São Paulo, 2007.

LOPES, Evandro J. Desenvolvimento de sistema de gaseificação via análise de emissões atmosféricas. 146 p. Curitiba: Universidade Federal do Paraná, 2014.

PAN, N. et al. Characterization of middle-temperature gasification coal tar. Part 1: Bulk properties and molecular compositions of distillates and basic fractions. Energy and Fuels, v. 26, n. 9, p. 5719-5728, 2012.

RIBEIRO, P. B. Investigação de coprodutos provenientes da gaseificação do carvão mineral de Candiota/RS. Bagé: Universidade Federal do Pampa, 2016.

SÁ, F. D.; GUTERRES F. P.; RAUPP, I. N.; MUNIZ, A. R. C.; RODRIGUES, R. Desenvolvimento e operação de uma planta piloto para a gaseificação do carvão mineral de 
Candiota. $8^{\circ}$ Salão Internacional de Ensino, Pesquisa e Extensão, Universidade Federal do Pampa, 2016.

SHREVE, R.N; BRINK Jr, J.A. Indústrias de Processos Químicos. $4^{\mathrm{a}}$ ed. Guanabara Koogan, S.A. Rio de Janeiro, 1980. 